\title{
Mechanism of exosomal miR-155 derived from bone marrow mesenchymal stem cells on stemness maintenance and drug resistance in myeloma cells
}

\author{
Xinyu Gao ${ }^{1,2}$, Jin Zhou ${ }^{1 *}$, Jinghua Wang ${ }^{2}$, Xiushuai Dong ${ }^{2}$, Yuying Chang ${ }^{2}$ and Yinglan Jin²
}

\begin{abstract}
Objective: This study was to explore the effect of exosomal miR-155 derived from bone marrow mesenchymal stem cells (BMSCs) on stemness maintenance and drug resistance in MPC-11 multiple myeloma cells.

Methods: MPC-11 cells were transfected with mimics or inhibitors of miR-155. miR-155 expression was detected by qRT-PCR, cell condition was observed, and the expression of stemness maintenance markers OCT-4 and Nanog was observed by immunofluorescence. The expression of proteins associated with the Hedgehog signaling pathway and drug resistance was evaluated by western blot. To investigate whether exosomes affect cell behavior by horizontal delivery of miR-155, MPC-11 cells were co-cultured with exosomes isolated from BMSCs that were transfected with mimics or inhibitors of miR-155. Cell proliferation and the expression of proteins related to stemness maintenance protein and drug resistance were examined.
\end{abstract}

Results: In function assays, after miR-155-mimics transfection, the expression levels of proteins related to stemness maintenance marker, Hedgehog signaling, and drug resistance were increased in MPC-11 cells. BMSC-derived exosomes carrying miR-155 inhibited apoptosis, promoted cell division, and upregulated the expression of protein associated with stemness maintenance, Hedgehog signaling, and drug resistance.

Conclusion: Therefore, our findings indicate that exosomal delivery of miR-155 exerted the same effect as transfection did on the stemness maintenance and drug resistance of multiple myeloma cells.

Keywords: Multiple myeloma, Exosomes, miR-155, Myeloma cells, Stemness maintenance, Drug resistance

\section{Background}

Multiple myeloma (MM) is a malignant tumor characterized by the proliferation of plasmacytes in the bone marrow microenvironment, and it is currently difficult to cure [1]. Immunomodulatory drugs such as bortezomib and thalidomide have anti-MM effects, indicating that maladjusted immune effector cells play an important role

\footnotetext{
*Correspondence: zhoujin_111@126.com

${ }^{1}$ Department of Hematology, The First Affiliated Hospital of Harbin Medical University, Harbin, Heilongjiang, China

Full list of author information is available at the end of the article
}

in MM [2-4]. Exosomes are vesicles with a diameter of $30-100 \mathrm{~nm}$ that are secreted by immune cells and cancer cells and exert immunomodulatory effects after external stimulation, participating in the formation of an immunosuppressive microenvironment in $\mathrm{MM}[5,6]$. In the tumor microenvironment, extracellular communication enables cells to coordinate and perform biological functions [7], and emerging evidence suggests that exosomes participate in tumor progression as a medium for cell communication [8]. In the progression of MM, exosomes regulate MM cells, mesenchymal stromal cells (MSC)

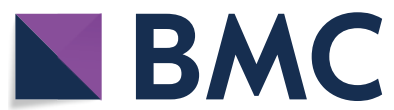

(c) The Author(s) 2021. Open Access This article is licensed under a Creative Commons Attribution 4.0 International License, which permits use, sharing, adaptation, distribution and reproduction in any medium or format, as long as you give appropriate credit to the original author(s) and the source, provide a link to the Creative Commons licence, and indicate if changes were made. The images or other third party material in this article are included in the article's Creative Commons licence, unless indicated otherwise in a credit line to the material. If material is not included in the article's Creative Commons licence and your intended use is not permitted by statutory regulation or exceeds the permitted use, you will need to obtain permission directly from the copyright holder. To view a copy of this licence, visit http://creativecommons.org/licenses/by/4.0/. The Creative Commons Public Domain Dedication waiver (http://creativeco mmons.org/publicdomain/zero/1.0/) applies to the data made available in this article, unless otherwise stated in a credit line to the data. 
and vascular endothelial cells (VEGF) in tumor microenvironment. (VEC), osteoclasts, immune cells and other cell interactions promote MM cell proliferation, angiogenesis, and the formation and differentiation of osteoclasts, which play an important role in MM immunosuppression [9]. Studies have suggested that secretion of exosome can act as a signal transduction medium to change the sensitivity of tumor to chemotherapy drugs and participate in tumor progress. Meanwhile, exosome can expel a variety of compound drugs out of tumor cells, reduce tumor cells' drug resistance, and thus lead to the failure of chemotherapy [10]. miRNAs are small noncoding RNAs that can regulate gene expression in human cells. Specific miRNAs regulate cytokine expression and orchestrate proliferation and differentiation of stromal cell lines involved in the composition of the extracellular matrix $[11,12]$. MiR-155 plays an important role in the drug resistance of various solid tumors such as glioma, non-small cell lung cancer, colorectal cancer, liver cancer, and breast cancer [13]. It also plays a crucial role in the occurrence and development of hematological tumors [14], but its specific underlying mechanism has not yet been clarified. Alexander et al. found that miR155 regulated inflammation in an endotoxin-inflamed mouse model, emphasizing that miR-155 is carried by exosomes secreted by dendritic cells and can be absorbed by neighboring dendritic cells to promote inflammation [15] and confirming that miR-155 can be transported by exosomes between cells. In MM, whether miR-155 is involved in the drug resistance of myeloma cells has not been reported. We speculate that miR-155 is delivered by exosomes to affect the stemness maintenance of myeloma cells, thus affecting drug resistance. In this study, exosomes were isolated from mouse bone marrow mesenchymal stem cells (BMSCs), and the effect of miR-155 on myeloma cells (showing the same stem characteristics as BMSCs [16]) on stemness maintenance and drug resistance in mice was determined. The findings provide directions and references for clinically biological targeted therapy of MM.

\section{Methods}

\section{Antibody and reagents}

The following antibodies and reagents were purchased: Western blot used antibodies CD63 (Bioswamp, rabbit, PAB33929), CD81(abcam, rabbit, ab109201), TSG101 (Bioswamp, rabbit, PAB32949), Hhip (Bioswamp, rabbit, PAB40945), Ptch1 (Bioswamp, rabbit, PAB30041), Smo (Bioswamp, rabbit, PAB33618), GLi (Bioswamp, rabbit, PAB32098), GLiA (Bioswamp, rabbit, PAB30738), MRP1(Bioswamp, rabbit, PAB33537), ABCG2(Bioswamp, rabbit, PAB34152), P-gp (Bioswamp, rabbit, PAB30805), GAPDH(Bioswamp, rabbit, PAB36269), Goat anti-Rabbit
IgG (Bioswamp, rabbit, PAB160011), flow cytometry used antibodies fluorescein isothiocyanate (FITC)-conjugated CD44 monoclonal antibody (eBioscience, 11-0441-82), allophycocyanin-conjugated CD29 (integrin beta 1) monoclonal antibody (eBioscience, 17-0291-82), FITCconjugated CD11b monoclonal antibody (eBioscience, 11-0112-41), FITC-conjugated Ly-6A/E (Sca-1) monoclonal antibody (eBioscience, 11-5981-82), immunofluorescence used Nano antibodys (rabbit, Mitaka, 14295-1-AP), OCT-4 antibody (rabbit, Abcam, ab181557), Alexa Fluor 594-conjugated goat anti-rabbit antibody (Bioswamp, PAB160018), SYBR Green PCR Kit (KAPA Biosystems, KM4101), Lipofectamine ${ }^{\circledR}$ RNAiMAX (Invitrogen, 13778030), RPMI-1640 (Hyclone, SH30809.01B), chemiluminescence kit (Millipore, WBKLS0010), Lipofectamine ${ }^{\circledR}$ RNAiMAX (Invitrogen, 13778030), Trizol (Ambion, 15596026), and reverse transcription kit (TAKARA, 639505).

\section{Mice}

The 4-week-old C57BL/6 mice (male) were from the Department of experimental animal, Harbin Medical University, weighing 16-18 g, and production license number SCXK (Hei) 2019-001. The study was approved by the Second Affiliated Hospital of Harbin Medical University Ethics Committee and adhered to the "Guidelines for Animal Care and Use of the Ethics Committee at Hospital of Harbin Medical University" (approval number sydw-2018-083).

\section{Mimics and inhibitors}

The Cbfa1, OC, PPAR 2 et al. primers, miR-155-mimics and miR-155-inhibitors sequence were synthesized by Guangzhou Ruibo Biotechnology Co., Ltd.

\section{BMSC separation and identification}

Male clean grade BALB/c mice (4-6 weeks) were housed at $22-26{ }^{\circ} \mathrm{C}$ in a 12 -h light/dark cycle. According to the method of Yan et al. [17], the bilateral femurs were extracted on mice and the femoral bones were cut to expose the bone marrow cavity. The bone marrow cavity was repeatedly washed with the culture solution to collect and culture bone marrow cells. BMSCs were cultured in RPMI-1640 medium containing 15\% fetal bovine serum (Gibco, 10270-106) and 1\% Penicillin Streptomycin Solution (Solarbio, P1400) at $37{ }^{\circ} \mathrm{C}$ in an incubator with $5 \% \mathrm{CO}_{2}$. Hematopoietic stem progenitor cells were isolated from the cells at passage 3 using CD11b magnetic beads. The expression of cell surface antigens CD11b, CD44, CD29, and SCA-1 was detected by flow cytometry. 


\section{Exosome separation and identification and interaction with MPC-11 cells}

The BMSCs were cultured in RPMI-1640 medium without FBS for $48 \mathrm{~h}$, and cell culture medium was collected. The culture medium was centrifuged at $500 \times g$ for $10 \mathrm{~min}$, and the supernatant was collected and centrifuged at $2000 \times g$ for $20 \mathrm{~min}$. The supernatant was collected again and centrifuged at $100,000 \times g$ for $70 \mathrm{~min}$. The precipitate was resuspended and centrifuged with a $40 \%$ sucrose gradient at $100,000 \times g$ for $70 \mathrm{~min}$. The supernatant was collected and centrifuged at $100,000 \times g$ for $70 \mathrm{~min}$, and the collected precipitate contained exosomes. Exosome was fixed with $2 \%$ glutaraldehyde (0.1 M PBS, pH7.4). Exosomes were isolated and observed under a transmission electron microscope. $1 \times 10^{6} \mathrm{MPC}-11$ cells interact with $50 \mu \mathrm{g}$ exosomes for $24 \mathrm{~h}$. The expression of exosomal markers CD63, CD81, and TSG101 was detected using western blot [18].

\section{Exosome morphological identification of electron microscope}

Exosome were fixed with $2 \%$ glutaraldehyde (0.1 M PBS, pH7.4) and integrated with nickel mesh and washing with PBS. The following is adding $1 \%$ glutaraldehyde dropwise to incubate for $5 \mathrm{~min}$ and washing with $\mathrm{ddH} 2 \mathrm{O}$ several times. Next is adding $4 \%$ uranium acetate to the sample and incubated for $5 \mathrm{~min}$. After drying, the exosome morphology was observed under the electron microscope.

\section{Cell transfection}

The multiple myeloma cell line MPC-11 (Wuhan University Cell Bank, GDC300) and BMSCs were cultured in RPMI-1640 medium at $37{ }^{\circ} \mathrm{C}$ in an incubator with $5 \%$ $\mathrm{CO}_{2} .3 \times 10^{5}$ cells in the logarithmic growth phase were seeded in 6-well plates with 2 -mL cell culture medium. For transfection, $100 \mathrm{pmol}$ of $\mathrm{miR}$ and $5 \mu \mathrm{L}$ of Lipofectamine ${ }^{\circledR}$ RNAiMAX were mixed with $250 \mu \mathrm{L}$ of OptiMEM and added to $500 \mu \mathrm{L}$ cell culture medium and then mixed with $1.5-\mathrm{mL}$ cell culture medium. The cells were divided into five groups: control, miR-155-mimics, miR-155-inhibitors, miR-155-mimics-NC, and miR-155-inhibitor-NC.

\section{RNA extraction and quantitative reverse-transcription polymerase chain reaction ( $q R T-P C R$ )}

Total RNA was extracted from cells using Trizol reagent, and cDNA was generated using the reverse transcription kit. qRT-PCR was performed on a CFX-Connect 96 instrument (Bio-Rad) using the SYBR Green Master Mix. The reaction mixture for qRT-PCR consisted of $10 \mu \mathrm{L}$ of SYBR Green Master Mix, $1 \mu \mathrm{L}$ of primer mix, $1 \mu \mathrm{L}$ of cDNA template, and $8 \mu \mathrm{L}$ of double distilled water. The conditions for qRT-PCR were as follows: pre-denaturation at $95{ }^{\circ} \mathrm{C}$ for $3 \mathrm{~min} ; 40$ cycles of denaturation at $95{ }^{\circ} \mathrm{C}$ for $5 \mathrm{~s}$, annealing at $56{ }^{\circ} \mathrm{C}$ for $10 \mathrm{~s}$, extension at $72{ }^{\circ} \mathrm{C}$ for $25 \mathrm{~s}$; fluorescence signal acquisition between 65 and $95^{\circ} \mathrm{C}$. Using U6 as the internal reference gene, the primer sequences of each gene are shown in Table 1. $2^{-\Delta \Delta C t}$ method was used to calculate the relative miR expression. The primers are listed in Table 1.

\section{Western blot}

Cells were homogenized in protein lysate buffer, and debris was removed by centrifugation at $12,000 \times g$ for $10 \mathrm{~min}$ at $4{ }^{\circ} \mathrm{C}$. After the addition of sample loading buffer, $50 \mu \mathrm{g}$ of protein samples was electrophoresed and transferred to polyvinylidene difluoride membranes. The blots were blocked for $2 \mathrm{~h}$ at room temperature with fresh 5\% nonfat milk in Tris-buffered saline/Tween 20 (TBST). The membranes were incubated with specific primary antibodies (CD63, CD81, TSG101, Hhip, Ptch1, Smo, Gli, GliA, MRP1, ABCG2, P-gp, GAPDH) in TBST overnight at $4{ }^{\circ} \mathrm{C}$. After three washes with TBST, the blots were incubated with secondary antibodies (goat anti-Rabbit IgG) for $1 \mathrm{~h}$, and the immunoreactive bands were visualized using an enhance chemiluminescence kit. The density of the immunoreactive bands was analyzed using TANON GIS software (TANON, China).

\section{Flow cytometric analysis of cell cycle}

The collected $10^{5}$ cell suspension was centrifuged at $1000 \times g$ for $5 \mathrm{~min}$, and the cell pellet was resuspended in $300 \mu \mathrm{L}$ of phosphate-buffered saline (PBS) containing $10 \%$ fetal bovine serum. Absolute ethanol $(700 \mu \mathrm{L})$

Table 1 Primer sequences for qRT-PCR

\begin{tabular}{ll}
\hline Primer & Sequence $\left.\mathbf{( 5}^{\prime} \mathbf{- 3} \mathbf{\prime}^{\prime}\right)$ \\
\hline Cbfa1-F & GTGTTCTAGCCAAATCCT \\
Cbfa1-R & TTATGGGTGTTCCTCTGT \\
OC-F & GGGCAATAAGGTAGTGAA \\
OC-R & GTAGATGCGTTTGTAGGC \\
PPARy2-F & GCAGAGCAAAGAGGTGGC \\
PPARy2-R & TTTATTCATCAGGGAGGC \\
adipsin-F & AGAATGCCTCGTTGGGTC \\
adipsin-R & CGCAGATTGCAGGTTGTC \\
GAPDH-F & CCTTCCGTGTTCCTAC \\
GAPDH-R & GACAACCTGGTCCTCA \\
miR-155-RT-F & CTCAACTGGTGTCGTGGAGTCGG \\
miR-155-RT-R & CAATTCAGTTGAGACCCCTAT \\
miR-155-F & GGGTTAATGCTAATTGTG \\
miR-155-R & AACTGGTGTCGTGGAGTCGGC \\
U6-F & CTCGCTTCGGCAGCACA \\
U6-R & AACGCTTCACGAATTTGCGT \\
\hline &
\end{tabular}



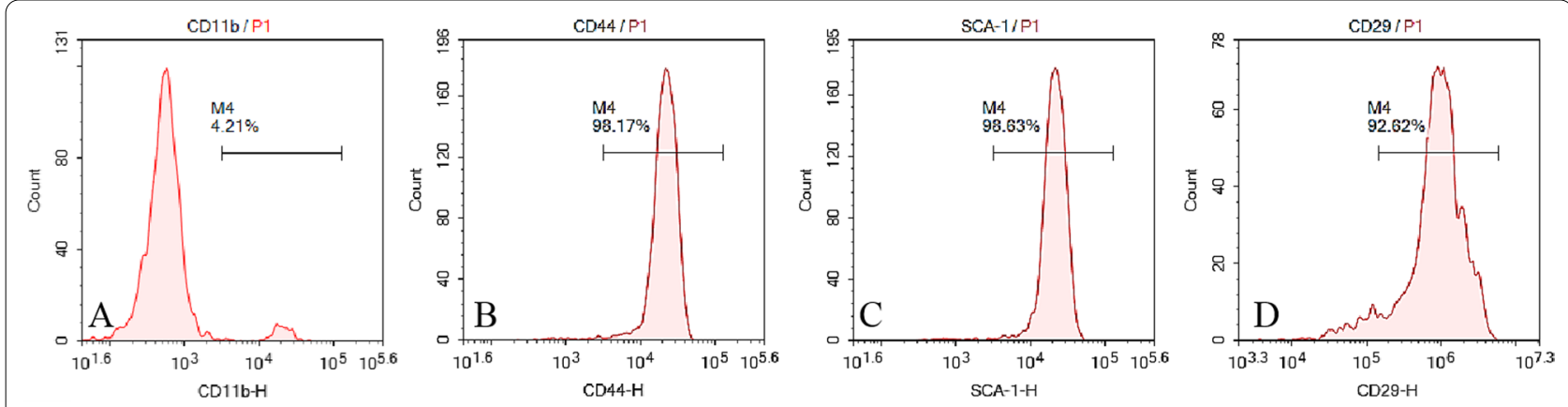

$\mathbf{E}$

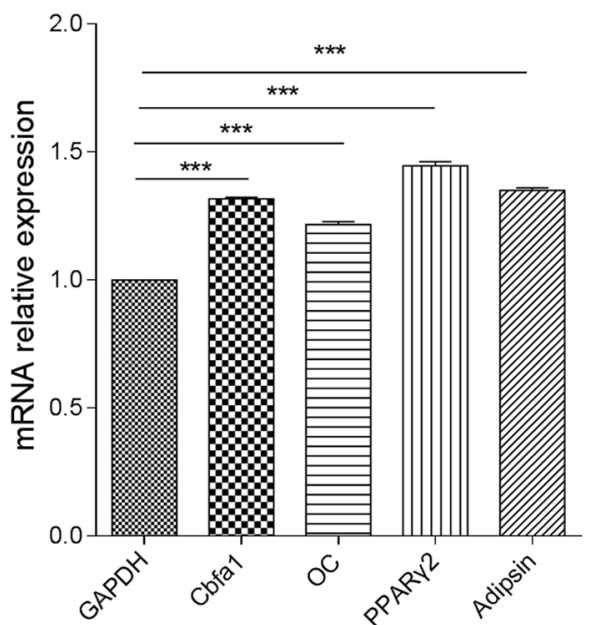

Fig. 1 Proportion of $\mathbf{a}$ CD11 b+, b CD44+, c SCA-1+, d CD29+ BMSCs, and e relative expression of Cbfa1, OC, PPARy2, Adipsin

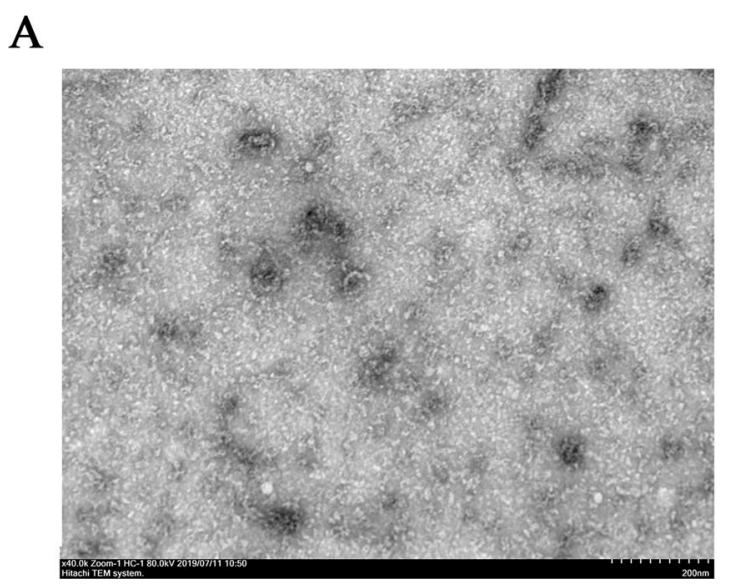

B

Exosome serum
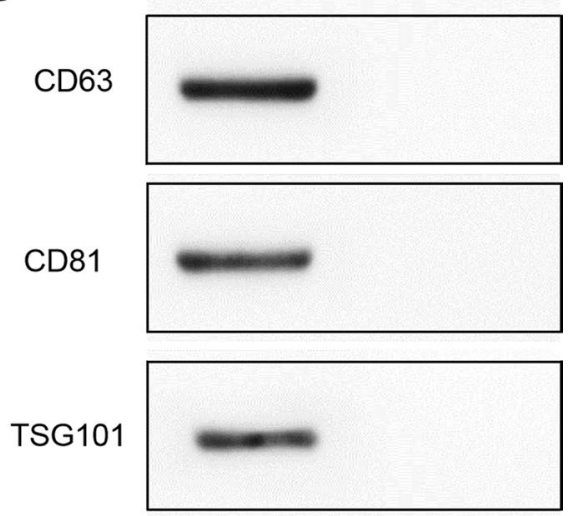

Fig. 2 Exosome identification

was added to fix the cells at $-20{ }^{\circ} \mathrm{C}$ for at least $24 \mathrm{~h}$. The fixed sample was centrifuged at $3000 \times g$ for $30 \mathrm{~s}$, and the cell pellet was suspended in $100 \mu \mathrm{L}$ of $1 \mathrm{mg} / \mathrm{mL}$ RNase A solution and incubated for $30 \mathrm{~min}$ at $37^{\circ} \mathrm{C}$. Propidium iodide $(400 \mu \mathrm{L}, 50 \mu \mathrm{g} / \mathrm{mL})$ was added, and the nuclei were stained for $10 \mathrm{~min}$ in the dark. Flow cytometry was performed to determine the DNA content of the cells and the proportion of cells in each phase of the cell cycle. 


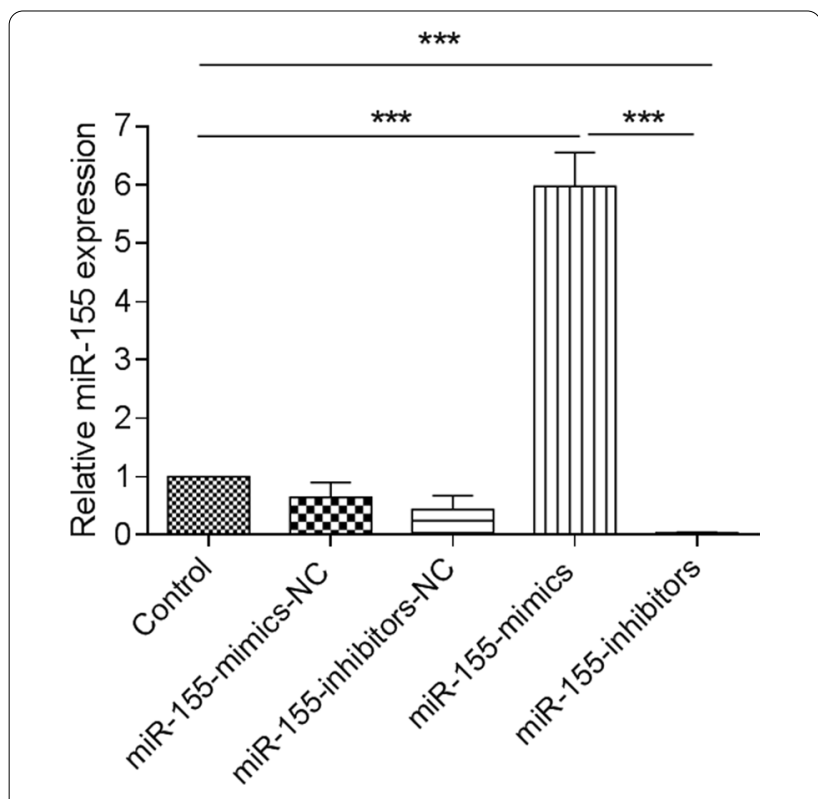

Fig. 3 Relative expression of miR-155. ${ }^{* * *} P<0.001$

of binding buffer. Then, $10 \mu \mathrm{L}$ of annexin V-FITC and $10 \mu \mathrm{L}$ of propidium iodide were added, mixed gently, and incubated at $4{ }^{\circ} \mathrm{C}$ in the dark for $30 \mathrm{~min}$. Binding buffer $(300 \mu \mathrm{L})$ was added, and flow cytometry was performed. The data were analyzed using NovoExpress software (ACEA, China).

\section{Immunofluorescence}

The cells were fixed with $4 \%$ paraformaldehyde at room temperature for $30 \mathrm{~min}$, washed with PBS, then permeabilized with $0.5 \%$ Triton X-100 at room temperature for $20 \mathrm{~min}$. After three washes with PBS, the cells were blocked with $5 \%$ bovine serum albumin at $37^{\circ} \mathrm{C}$ for $1 \mathrm{~h}$, incubated with primary antibodies (Nanog, OTC-4) at room temperature for $1 \mathrm{~h}$, and washed three times with PBS. Next, the cells were incubated with secondary antibody (Alexa Fluor 594-conjugated Goat Anti-Rabbit) at $37{ }^{\circ} \mathrm{C}$ for $1 \mathrm{~h}$ and washed three times with PBS. Cell nuclei were stained with DAPI for $20 \mathrm{~min}$, and the cells were observed under a confocal laser scanning fluorescence microscope (Nikon, C2).

The results were analyzed using NovoExpress software (ACEA, China).

\section{Flow cytometry analysis of apoptosis}

Ice-cold PBS $(1 \mathrm{~mL})$ was added to the collected cells, which were shaken gently and centrifuged at $4{ }^{\circ} \mathrm{C}$ at $1000 \times g$ for $5 \mathrm{~min}$. The cells were resuspended in $200 \mu \mathrm{L}$

\section{Cell Counting Kit 8 (CCK8) assay}

Cells in the logarithmic growth phase were seeded in 96-well plate at $5 \times 10^{3}$ cells/well and transfected with mimics for $24 \mathrm{~h}$. Then, $10 \mu \mathrm{L}$ of CCK8 solution was added to each well and the cells were further incubated for $4 \mathrm{~h}$. The absorbance of each well was measured at

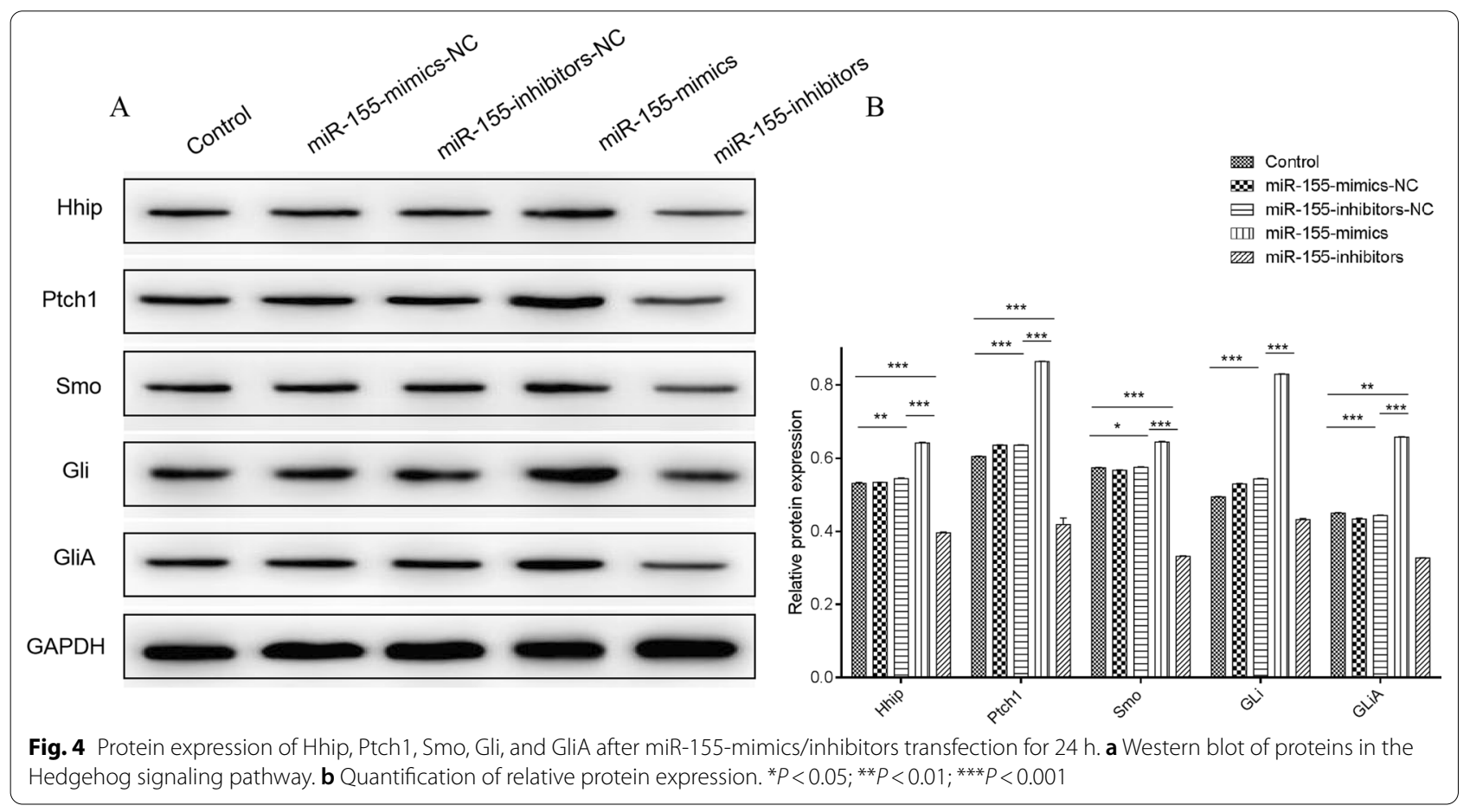



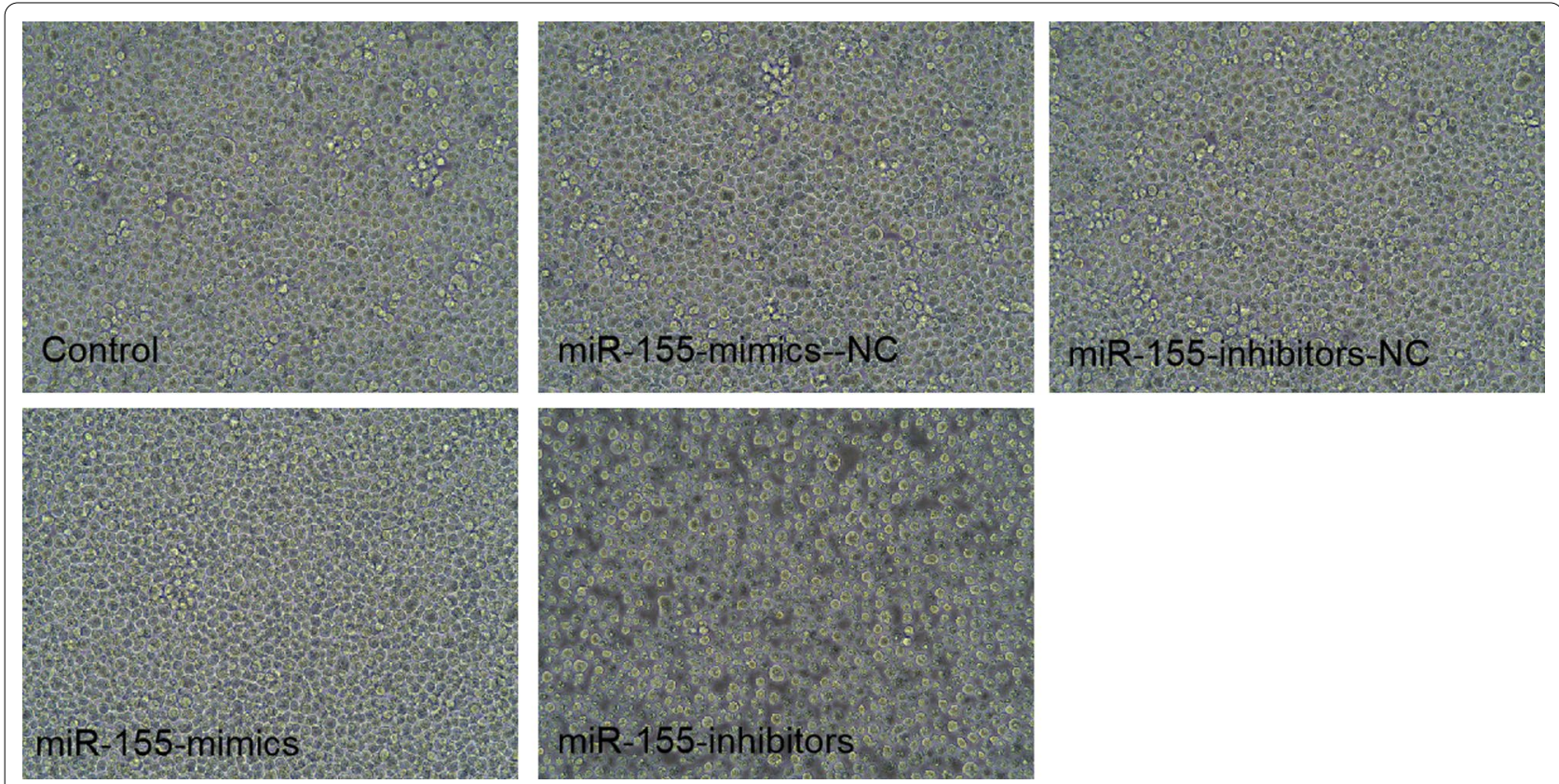

Fig. 5 Cell condition after miR-155-mimics/inhibitors transfection for $24 \mathrm{~h}$. Images were acquired at 200x

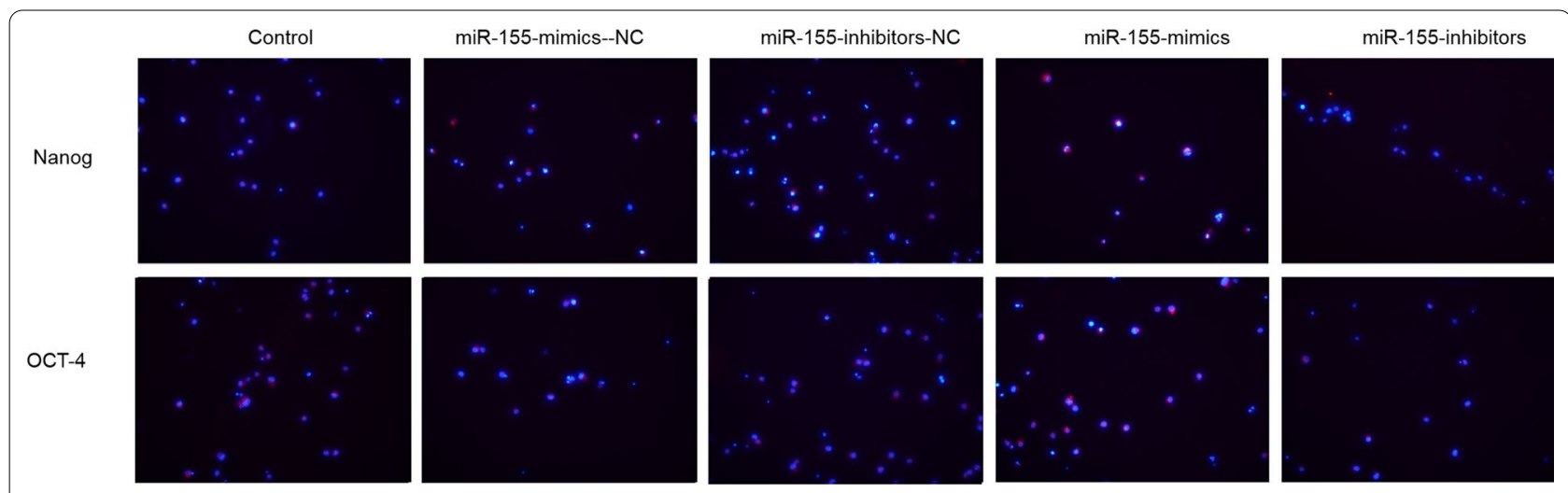

Fig. 6 Expression of OCT-4 and Nanog after miR-155-mimics/inhibitors transfection for $24 \mathrm{~h}$. Blue indicates the nucleus, red indicates Nanog and OCT-4 protein. Images were acquired at $200 x$

$450 \mathrm{~nm}$ using an enzyme-linked immunoassay detector (ALL FOR LIFE SCIENCE, AMR-100).

\section{Statistical analysis}

All experiments were performed in triplicate $(n=3)$, and the data are expressed as means $\pm S E$ of the mean. All statistical analyses were performed using the GraphPad ProPrism 5.0 (San Diego, CA) software package. Student's t test and two-way analysis of variance were employed to analyze the differences between treatment groups. $P<0.05$ was considered to be statistically significant.
Result

\section{BMSC identification}

Hematopoietic stem progenitor cells with the surface marker CD11b account for a small proportion of BMSCs, and most BMSCs express CD44, SCA-1, and CD29. The proportion (Fig. 1) of CD44+, SCA-1+, and CD29+ cells was $98.17 \%, 98.63 \%$, and $92.62 \%$, respectively. In addition, BMSC osteogenic marker genes Cbfa1 and osteocalcin (OC) and adipogenic marker genes PPAR 2 and adipsin mRNA were detected by qRT-PCR, which result show the Cbfa1, OC, PPAR 2 , adipsin abundantly expressed. These two results indicate that BMSCs was successfully separated. 


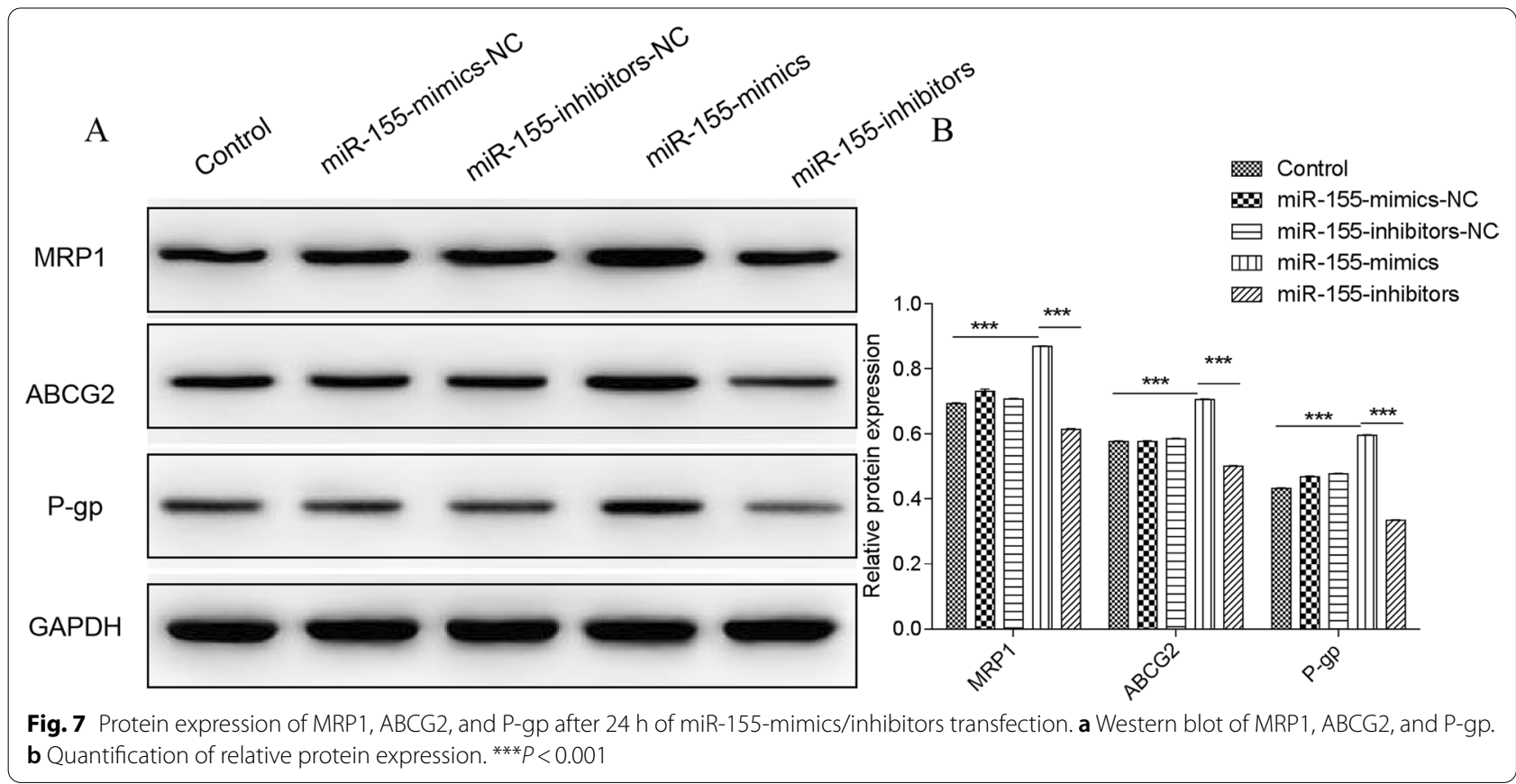

\section{Exosome identification}

The exosome markers CD63, CD81, and TSG101 were detected in the precipitate obtained by centrifugation as in Fig. 2, indicating that exosome separation was successful.

\section{MiR-155 detection}

As shown in Fig. 3, $24 \mathrm{~h}$ after MPC-11 cells were subjected to transfection, miR-155 was abundantly expressed in the miR-155-mimics group and was significantly different from that in the control and miR-155-inhibitors group $(P<0.001)$. The miR-155 expression in the miR155 -inhibitor group was significantly lower than that in the control group $(P<0.001)$.

\section{Expression of proteins in Hedgehog signaling pathway after miR-155-mimics/inhibitors transfection}

Our findings indicate that exosomal delivery of miR155 exerted the same effect as transfection did on the stemness maintenance and drug resistance of multiple myeloma cells (Additional file 1). After MPC-11 cells were transfected with miR-155-mimics/inhibitors for $24 \mathrm{~h}$, the expression of proteins associated with the Hedgehog signaling pathway (Hhip, Ptch1, Smo, Gli, and GliA) was altered significantly. In Fig. 4, miR-155-mimics significantly increased the expression of these proteins compared to that of the control group $(P<0.05)$, whereas miR-155-inhibitors significantly reduced their expression compared with that of the control group $(P<0.05)$. There was no significant difference between
miR-155-mimics-NC, miR-155-inhibitors-NC, and the control.

Cell condition after miR-155-mimics/inhibitors transfection To confirm whether transfection of miR-155 was involved in cell viability, we transfected MPC-11 cells with miR-155-mimics and inhibitors. After incubated miR-155-mimics for $24 \mathrm{~h}$, cell viability was increased compared with controls (Fig. 5). While the miR-155-inhibitors group were in poor condition, which presented cells atrophy and shed and terrible morphology. The cell condition in the NC group is similar to the control group.

\section{Stemness maintenance after miR-155-mimics/inhibitors transfection}

After $24 \mathrm{~h}$ of intervention, miR-155-mimics increased the expression of the stemness maintenance marker proteins OCT-4, and Nanog compared with that in the control group just like Fig. 6, whereas that in the miR-155-inhibitors group was reduced. No obvious differences were observed between the miR-155-mimics-NC, miR-155-inhibitors-NC, and control groups.

\section{Expression of drug resistance markers} after miR-155-mimics/inhibitors transfection

As shown in Fig. 7, miR-155-mim significantly increased the expression of drug resistance-associated proteins MRP1, ABCG2 and P-gp compared with the control group $24 \mathrm{~h}$ after transfection $(P<0.001)$. However, miR155 -inhibitors significantly reduced the expression of 


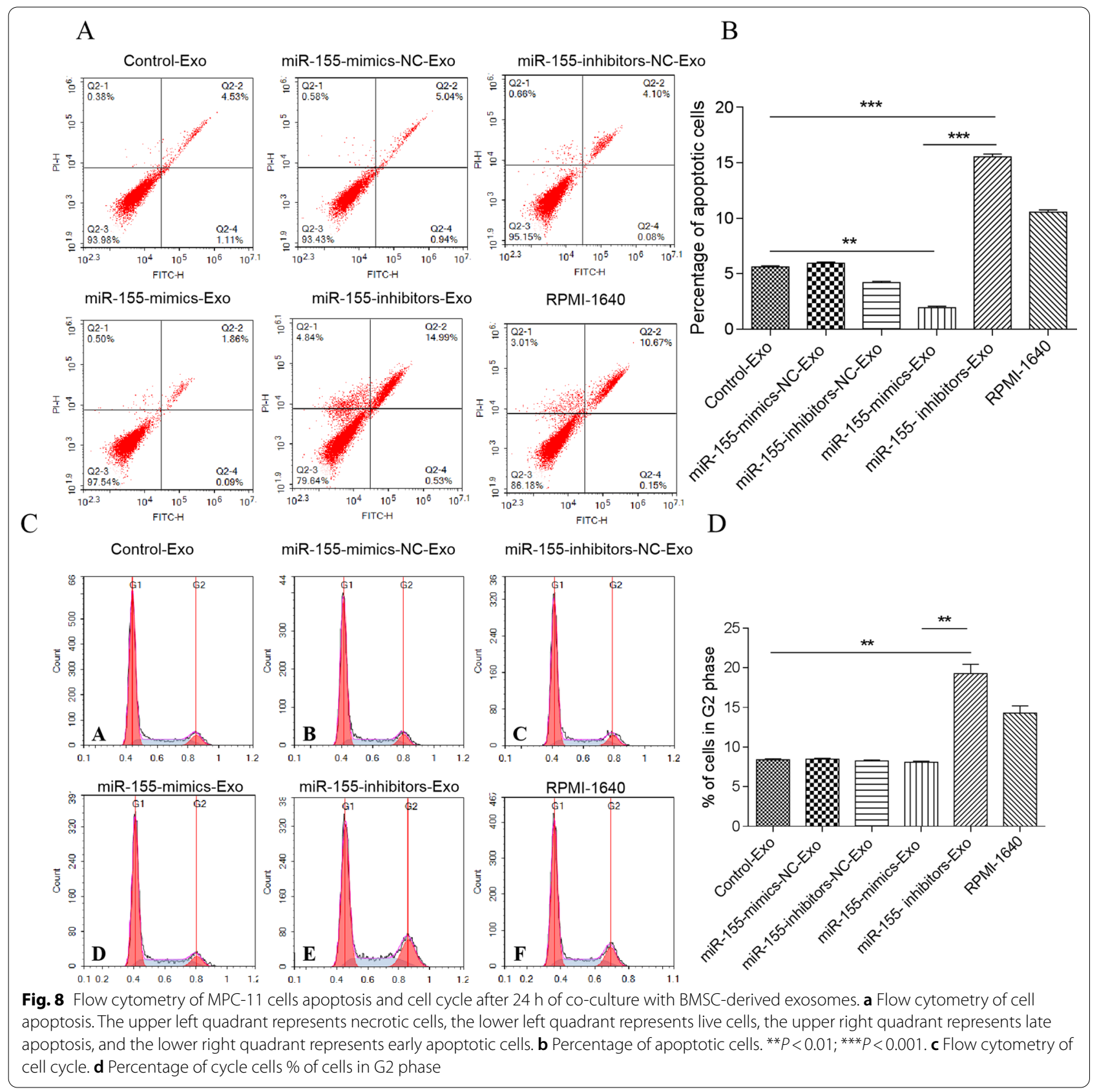

these proteins $(P<0.001)$. No obvious differences were observed between the miR-155-mimics-NC, miR-155-inhibitors-NC, and control groups.

Effect of BMSC-derived exosomes on MPC-11 cell apoptosis MPC-11 cells were co-cultured with BMSC-derived exosomes for $24 \mathrm{~h}$. In Fig. 8, the apoptosis of MPC-11 cells co-cultured with exosomes derived from miR155-mimics (miR-155-mimics-Exo)-transfected BMSCs was significantly lower than that of MPC-11 cells cocultured with exosomes from non-transfected (control)
BMSCs $(P<0.01)$, whereas that of the miR-155-inhibitors-Exo group was significantly higher than that of Control-Exo $(P<0.001)$ and miR-155-mimics-Exo groups $(P<0.001)$. There was no significant difference between the $\mathrm{NC}$ and control groups.

miR-155-mimics-Exo and NC did not significantly affect cell cycle progression, whereas the proportion of cells in the G2 phase was significantly increased by miR155-inhibitors-Exo compared to that in the control and miR-155-mimics-Exo groups $(P<0.01)$. 

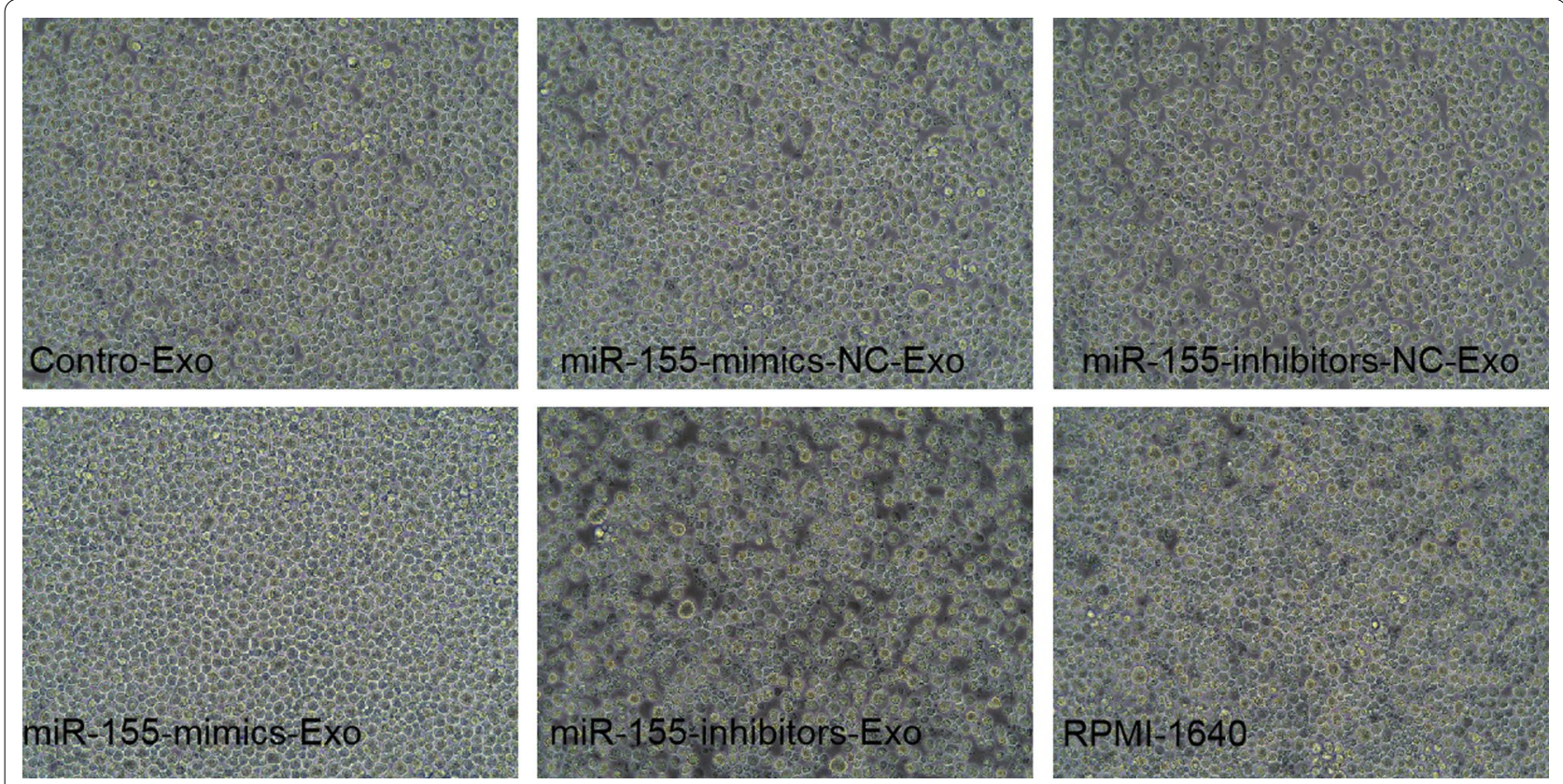

Fig. 9 MPC-11 cell condition after $24 \mathrm{~h}$ of co-culture with BMSC-derived exosomes. Images were acquired at 200

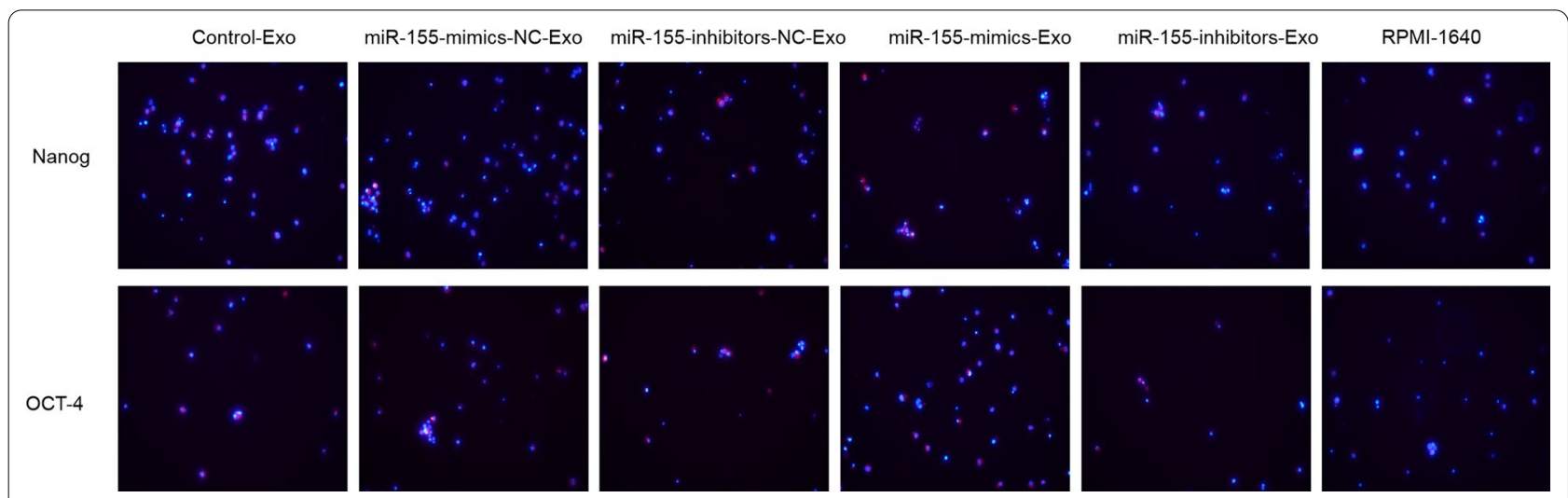

Fig. 10 Expression of Nanog and OCT-4 after $24 \mathrm{~h}$ of co-culturing MPC-11 cells with BMSC-derived exosomes. Blue indicates the nucleus, red indicates Nanog and OCT-4 protein. Images were acquired at 200

Effect of BMSC-derived exosomes on MPC-11 cell condition After $24 \mathrm{~h}$ of co-culturing MPC-11 cells with BMSCderived exosomes, the cell growth status of miR155-mimics-Exo group was good as shown in Fig. 9, which presented favorable cell morphology and uniform growth, while miR-155-inhibitors-Exo group were in poor condition, which presented cells atrophy and shed and terrible morphology. The cell condition in the NC group is similar to the control group.

\section{Effect of BMSC-derived exosomes on stemness} maintenance in MPC-11 cells

After $24 \mathrm{~h}$ of co-culturing MPC-11 cells with BMSCderived exosomes, the expression of Nanog and OCT-4 was increased by miR-155-mimics-Exo and decreased by miR-155-inhibitor-Exo compared to that in the control groups (Fig. 10).

\section{Effect of BMSC-derived exosomes on Hedgehog signaling pathway}

In Fig. 11, after $24 \mathrm{~h}$ of co-culturing MPC-11 cells with BMSC-derived exosomes, miR-155-mimics-Exo significantly upregulated the expression of proteins associated 

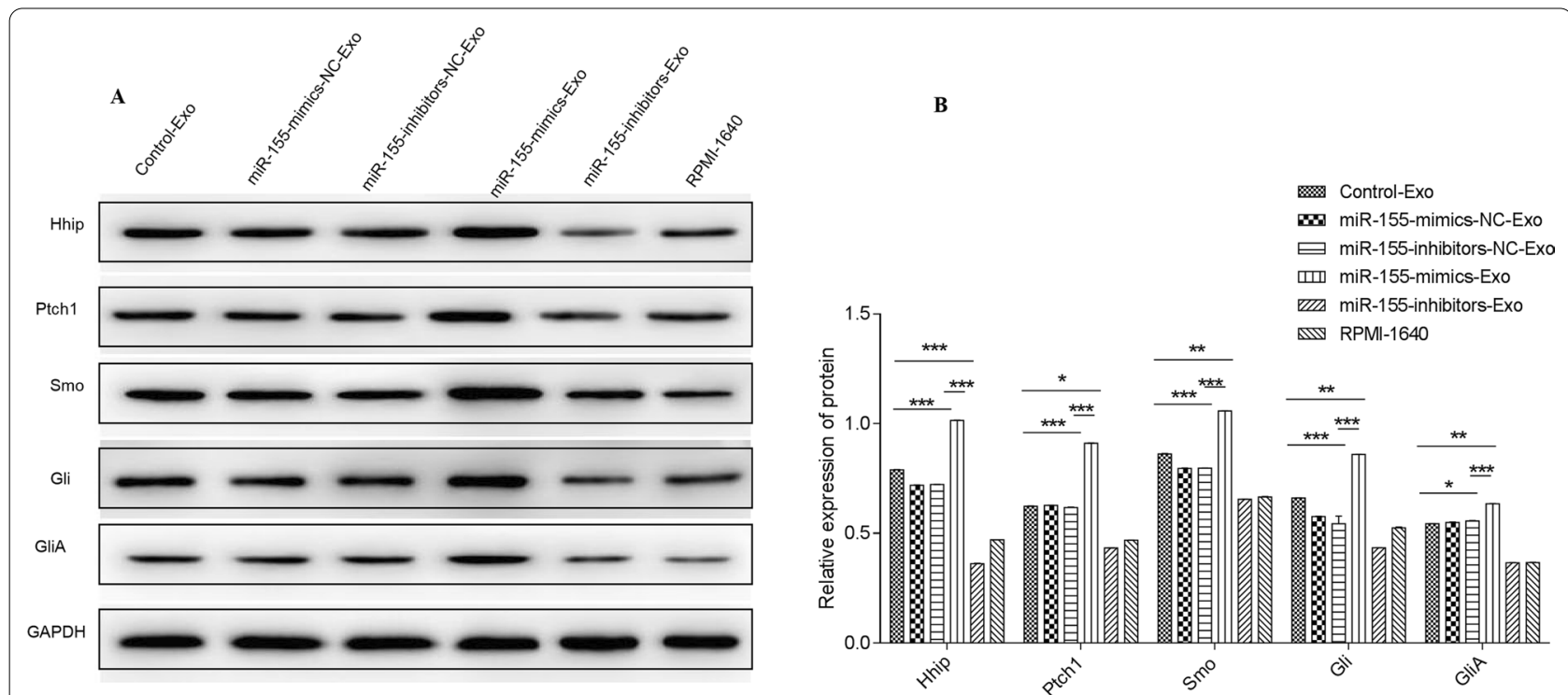

Fig. 11 Protein expression of Hhip, Ptch1, Smo, Gli, and GliA after $24 \mathrm{~h}$ of co-culturing MPC-11 cells with BMSC-derived exosomes. ${ }^{*} P<0.05$; ${ }^{*} P<0.05 ;{ }^{* *} P<0.001$

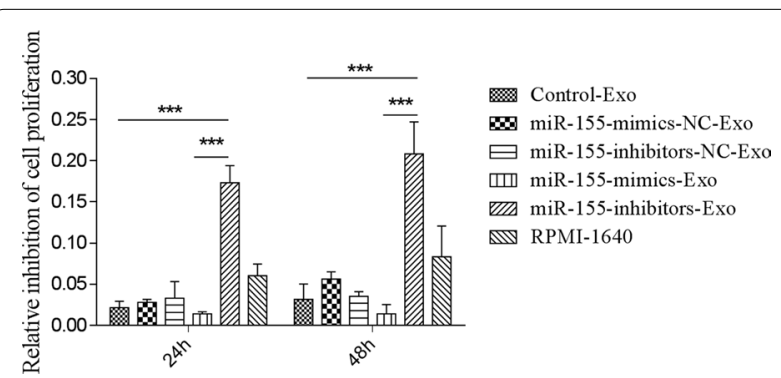

Fig. 12 Inhibition of MPC-11 cell proliferation after 24 and $48 \mathrm{~h}$ of co-culturing MPC-11 cells with BMSC-derived exosomes. ${ }^{* *} P<0.001$

with the Hedgehog signaling pathway (Hhip, Ptch1, Smo, Gli, and GliA), which is related to stemness maintenance, compared to Control-Exo $(P<0.05)$. These proteins were significantly downregulated by miR-155-inhibitors-Exo $(P<0.05)$ compared to Control-Exo.

\section{Effect of BMSC-derived exosomes on MPC-11 cell proliferation}

After $24 \mathrm{~h}$ of co-culturing MPC-11 cells with BMSCderived exosomes, the relative inhibition of MPC-11 cell proliferation induced by miR-155-mimics-Exo was lower than that induced by Control-Exo, but there was no significant difference (Fig. 12). However, miR-155-inhibitors-Exo induced significantly higher inhibition of MPC-11 cell proliferation than that induced by ControlExo and miR-155-mimics-Exo $(P<0.001)$. The same trend was observed at $48 \mathrm{~h}$.

\section{MiR-155-mimics promoted the expression of drug resistance-related proteins}

After $24 \mathrm{~h}$, the morphological changes before and after intervention were observed with 200 times light microscope. Bortezomib at different concentrations $(0.01$, $0.1,1,5,10 \mathrm{nM})[1]$ and dexamethasone $(0.01,0.1,1,5$, $10 \mathrm{uM})$ were used to intervene in the miR-155-mimics group and the control group. Drug sensitivity of MPC-11 cells in each group was observed after $24 \mathrm{~h}$. At the same time, the expressions of MRP1, ABCG2 and P-GP in all groups were observed with Western blot (Fig. 13).

\section{Discussion}

MM is also known as plasma cell myeloma and accounts for $1 \%$ of all tumors and $13 \%$ of blood tumors. Genome sequencing and analysis found that genes involved in protein translation, including methylation genes and those involved in blood clotting, have undergone mutations in MM patients. Mutations in signaling pathways such as nuclear factor- $\mathrm{kB}$ were also discovered [19]. The genetic complexity of MM makes it difficult to target mutations or specific signaling pathways. Studies have reported that the incidence of MM is closely related to the bone marrow microenvironment [20], and the identification of biological targets from the cell or tumor microenvironment is an urgent issue. miR-155 participates in various physiological activities and has become a therapeutic target and biomarker in many tumors. Feng et al. reported that miR-155 promoted the proliferation, migration, and colony formation of $\mathrm{MM}$ cell 


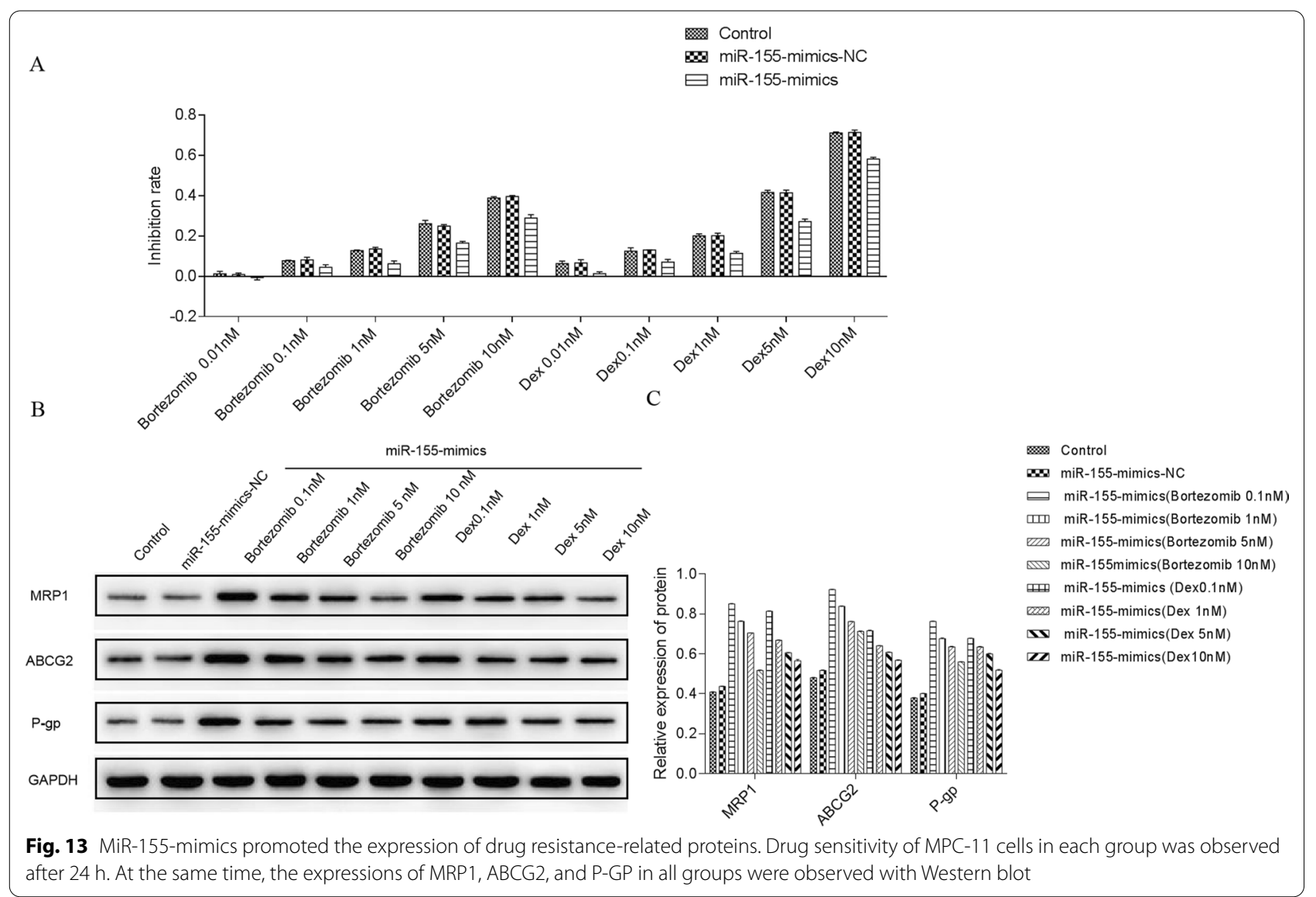

lines (RPMI-8266 and U266) through in vitro interference experiments and demonstrated that miR-155 suppressed the expression of the tumor suppressor gene SOCS1, thereby regulating JAK/STAT signaling [21]. A recent study showed that miR-155 plays an important role in the development of drug resistance in a variety of solid tumors, but its specific mechanism in blood tumors, especially MM, has not been elucidated [13]. We transfected the MM cell line MPC-11 with mimics or inhibitors of miR-155 and found that after miR-155 was successfully expressed in MPC-11 cells after $24 \mathrm{~h}$ of miR155-mimics transfection. The Hedgehog (Hh) signaling pathway plays a crucial role in maintaining the stemness of MM cells, as it can inhibit clonal expansion and promote the terminal differentiation of MM stem cells [22]. OCT-4 is a member of the POU domain transcription factor family that is usually expressed on pluripotent stem cells and plays a vital role in maintaining embryonic development and the proliferation and differentiation of stem cells. Nanog plays a momentous role in maintaining the self-renewal of cancer cells and the characteristics of cancer stem cells. Nanog and OCT-4 overexpression mediate the drug sensitivity and proliferation of various tumor cells [23]. After miR-155-mimics transfection, the expression of proteins involved in the Hedgehog signaling pathway, namely Hhip, Ptch1, Smo, Gli, and GliA (an activated form of Gli), was increased significantly. Moreover, OCT-4 and Nanog were significantly upregulated, indicating that miR-155 promoted stemness maintenance in MPC-11 cells. The drug resistance-related proteins MRP1, ABCG2, and P-gp play critical roles in drug sensitivity and confer drug resistance to cells. After miR-155-mimics transfection, the expression of MRP1, ABCG2, and P-gp increased significantly compared with that in control cells, indicating that miR-155 enhanced the drug resistance of MPC-11 cells. In the bone marrow microenvironment, MM cells interact with bone cells to enhance bone resorption activity and destroy new bone formation. In turn, BMSCs provide a framework for survival and drug resistance [24]. Peacock et al. found that exosomes are an important medium for crosstalk between MM cells and bone marrow microenvironment. Exosomes produced in the tumor microenvironment can interact with target cells through the following mechanisms: (1) direct stimulation of ligands expressed on the surface of the target cell membrane; (2) receptor transfer between the tumor and the target cell; (3) horizontal transfer of genetic information (miRNAs, mRNA, etc.) to 
target cells; (4) direct stimulation of ligands on the membrane surface of target cells through endocytosis [15, 25]. To investigate whether miR-155-mimics/inhibitors can affect MPC-11 cells by exosomal transfer, we isolated exosomes from BMSCs that were transfected with miR155-mimics/inhibitors and co-cultured MPC-11 cells with the exosomes for $24 \mathrm{~h}$. We observed that miR-155 was delivered by exosomes and promoted the expression of proteins in the Hedgehog signaling pathway as well as OCT-4 and Nanog, indicating that miR-155-mimicsExo promoted stemness maintenance in MPC-11 cells. In addition, miR-155-mimics-Exo promoted the expression of drug resistance-related proteins MRP1, ABCG2, and P-gp, suggesting that miR-155 increased the drug resistance of MPC-11 cells. It is worth noting that miR155-mimics-Exo induced the lowest number of apoptotic cells, indicating that miR-155 can inhibit apoptosis. In addition, miR-155-inhibitors induced the highest proportion of cells in the G2 phase, demonstrating that miR155-mimics promoted cell division.

In summary, miR-155 promoted cell growth and stemness maintenance and enhanced the drug resistance of MPC- 11 cells. In addition, miR-155 was horizontally delivered by exosomes to produce the same effect.

\section{Abbreviations \\ BMSCs: Bone marrow mesenchymal stem cells; MM: Multiple myeloma; FITC: Flow cytometry used antibodies Fluorescein isothiocyanate; TBST: Tris-buff- ered saline/Tween 20; PBS: Phosphate-buffered saline; OC: Osteocalcin; Hh: Hedgehog.}

\section{Supplementary Information}

The online version contains supplementary material available at https://doi. org/10.1186/s13018-021-02793-9.

Additional file 1. BMSC-derived exosomes carrying miR-155 inhibited apoptosis, promoted cell division, and upregulated the expression of protein associated with stemness maintenance, Hedgehog signaling, and drug resistance.

\section{Acknowledgements}

Not applicable.

\section{Authors' contributions}

JZ conceived and designed the experiments; XYG performed the experiments; $J H W$ and XSD done statistical analysis; XYG, YYC, YLJ wrote the paper; all authors read and approved the final manuscript.

\section{Funding}

Not applicable.

\section{Availability of data and materials}

The datasets used and/or analyzed during the current study are available from the corresponding author on reasonable request.

\section{Declarations}

Ethics approval and consent to participate

The study was approved by the Second Affiliated Hospital of Harbin Medical University Ethics Committee and adhered to the "Guidelines for Animal Care and Use of the Ethics Committee at Hospital of Harbin Medical University" (approval number sydw-2018-083).

\section{Consent for publication}

Approve.

\section{Competing interests}

The authors declare that they have no competing interests.

\section{Author details}

${ }^{1}$ Department of Hematology, The First Affiliated Hospital of Harbin Medical University, Harbin, Heilongjiang, China. ${ }^{2}$ Department of Hematology, The Second Affiliated Hospital of Harbin Medical University, Harbin, Heilongjiang, China.

Received: 29 July 2021 Accepted: 12 October 2021

Published online: 24 October 2021

\section{References}

1. Palumbo A. Multiple myeloma. Curr Opin Oncol. 2012;24(Suppl 2(7)):S1.

2. Mcbride A, Ryan PY. Proteasome inhibitors in the treatment of multiple myeloma. Expert Rev Anticancer Ther. 2013;13(3):339-58.

3. Huang J, Phillips S, Byrne M, et al. Lenalidomide vs bortezomib maintenance choice post-autologous hematopoietic cell transplantation for multiple myeloma. Bone Marrow Transplant. 2018;53:701-7.

4. Murray MY, Rushworth SA, Zaitseva L, et al. Attenuation of dexamethasone-induced cell death in multiple myeloma is mediated by miR-125b expression. Cell Cycle. 2013;12(13):2144-53.

5. Yang $Y, Y e Y$, Su X, et al. MSCs-derived exosomes and neuroinflammation, neurogenesis and therapy of traumatic brain injury. Front Cell Neurosci. 2017;11(49):55.

6. Simons M, Raposo G. Exosomes-vesicular carriers for intercellular communication. Curr Opin Cell Biol. 2009;21(4):575-81.

7. laccino E, Mimmi S, Dattilo V, et al. Monitoring multiple myeloma by idiotype-specific peptide binders of tumor-derived exosomes. Mol Cancer. 2017:16(1):159.

8. Singla DK. Stem cells and exosomes in cardiac repair. Curr Opin Pharmacol. 2016;27:19.

9. Moloudizargari M, Abdollahi M, Asghari $\mathrm{MH}$, et al. The emerging role of exosomes in multiple myeloma. Blood Rev. 2019;38:100595.

10. Harada T, Yamamoto H, Kishida S, et al. Wnt5b-associated exosomes promote cancer cell migration and proliferation. Cancer Sci. 2017:108(1):42-52.

11. Giordano L, Porta GD, Peretti GM, et al. Therapeutic potential of microRNA in tendon injuries. Br Med Bull. 2020;133(1):79-94.

12. Oliviero A, Della Porta G, Peretti GM, et al. MicroRNA in osteoarthritis: physiopathology, diagnosis and therapeutic challenge. Br Med Bull. 2019:130(1):137-47.

13. Bayraktar R, Van RK. miR-155 in cancer drug resistance and as target for miRNA-based therapeutics. Cancer Metastasis Rev. 2018;37(1):33-44.

14. Jurkovicova D, Magyerkova M, Kulcsar L, et al. miR-155 as a diagnostic and prognostic marker in hematological and solid malignancies. Neoplasma. 2014;61(3):241-51.

15. Alexander $M, H u R$, Runtsch $M C$, et al. Exosome-delivered microRNAs modulate the inflammatory response to endotoxin. Nat Commun. 2015;6:7321.

16. Matsui W, Wang Q, Barber JP, et al. Clonogenic multiple myeloma progenitors, stem cell properties, and drug resistance. Can Res. 2008;68(1):190-7.

17. Xing Y, Miaomiao L, Min Z, et al. Study on bone marrow hematopoietic function in rats with Qi deficiency model. Diet Health. 2016;3(22):44-5 ((in Chinese)). 
18. Peinado H, Alečković M, Lavotshkin S, et al. Melanoma exosomes educate bone marrow progenitor cells toward a pro-metastatic phenotype through MET. Nat Med. 2012;18(6):883-91.

19. Chapman MA, Lawrence MS, Keats JJ, et al. Initial genome sequencing and analysis of multiple myeloma. Nature. 2011;471(7339):467-72.

20. Ribatti D, Nico B, Vacca A. Importance of the bone marrow microenvironment in inducing the angiogenic response in multiple myeloma. Oncogene. 2006;25(31):4257-66.

21. Feng M, Luo X, Gu C, et al. Seed targeting with tiny anti-miR-155 inhibits malignant progression of multiple myeloma cells. J Drug Target. 2015;23(1):59-66.

22. Peacock CD, Wang Q, Gesell GS, et al. Hedgehog signaling maintains a tumor stem cell compartment in multiple myeloma. Proc Natl Acad Sci USA. 2007;104(10):4048-53.

23. Yin X, Zhang BH, Zheng SS, et al. Coexpression of gene Oct4 and Nanog initiates stem cell characteristics in hepatocellular carcinoma and promotes epithelial-mesenchymal transition through activation of Stat3/ Snail signaling. J Hematol Oncol. 2015;8(1):1-13.

24. Raimondi L, De LA, Carina V, et al. Contribution of multiple myelomaderived exosomes to bone disease. Bone Abstracts. 2016;5:P117.

25. Ji H, Greening DW, Barnes TW, et al. Proteome profiling of exosomes derived from human primary and metastatic colorectal cancer cells reveal differential expression of key metastatic factors and signal transduction components. Proteomics. 2013;13(10-11):1672.

\section{Publisher's Note}

Springer Nature remains neutral with regard to jurisdictional claims in published maps and institutional affiliations.
Ready to submit your research? Choose BMC and benefit from:

- fast, convenient online submission

- thorough peer review by experienced researchers in your field

- rapid publication on acceptance

- support for research data, including large and complex data types

- gold Open Access which fosters wider collaboration and increased citations

- maximum visibility for your research: over 100M website views per year

At BMC, research is always in progress.

Learn more biomedcentral.com/submissions 